\title{
Burden and Characteristics of Severe Chronic Hypoxemia in a Real-World Cohort of Subjects with COPD
}

\author{
Maéva Zysman (D) \\ Gaëtan Deslee ${ }^{2}$ \\ Thierry Perez $\mathbb{1 D}^{3}$ \\ Pierre-Régis Burgel $\mathbb{D}^{4}$ \\ Olivier Le Rouzic (D) ${ }^{3}$ \\ Graziella Brinchault-Rabin ${ }^{5}$ \\ Pascale Nesme-Meyer ${ }^{6}$ \\ Isabelle Court-Fortune $\mathbb{D}^{7}$ \\ Gilles Jebrak ${ }^{8}$ \\ Pascal Chanez ${ }^{9}$ \\ Denis Caillaud (D) ${ }^{10}$ \\ Jean-Louis Paillasseur ${ }^{\prime \prime}$ \\ Nicolas Roche $\mathbb{I D}^{4}$ \\ 'Pulmonary Department, Pôle Cardio- \\ thoracique, CHU Haut-Lévèque, INSERM \\ UI045, Bordeaux, France; ${ }^{2}$ Pulmonary \\ Department, Maison Blanche University \\ Hospital, INSERM U0 I250, Reims, France; \\ ${ }^{3}$ University Lille, CNRS, INSERM, CHU Lille, \\ Institut Pasteur de Lille, UI019 - UMR \\ 9017 - CIIL - Center for Infection and \\ Immunity of Lille, Lille, France; ${ }^{4}$ Respiratory \\ Medicine, Cochin Hospital, AP-HP and \\ Université de Paris, Institut Cochin, INSERM \\ UI016, Paris, France; ${ }^{5}$ Service de \\ Pneumologie, Hôpital Pontchaillou, Rennes, \\ France; ${ }^{6}$ Service de Pneumologie, Hôpital de \\ la Croix-Rousse, Lyon, France; ${ }^{7}$ Service de \\ Pneumologie, CHU Saint Etienne, Saint \\ Etienne, France; ' 8 Service de Pneumologie, \\ Hôpital Bichat, AP-HP, Paris, France; \\ ${ }^{9}$ Département des Maladies Respiratoires, \\ AP-HM, Université de la Méditerranée, \\ Marseille, France; ${ }^{10}$ Service de Pneumologie, \\ Hôpital Gabriel Montpied, CHU, Clermont- \\ Ferrand, France; "'EFFI-STAT, Paris, France
}

Correspondence: Maéva Zysman

Avenue de Magellan, Service des Maladies

Respiratoires, $\mathrm{CHU}$ Haut Lévèque,

Pessac, 33600, France

Tel +33556795679

Email maeva.zysman@chu-bordeaux.fr
Background: Chronic respiratory failure may occur as a consequence of chronic obstructive pulmonary disease (COPD) and is associated with significant morbidity and mortality. Hypoxemia is determined by underlying disease characteristics and comorbidities. Severe hypoxemia is typically only found in subjects with severe airflow obstruction $\left(\mathrm{FEV}_{1}<50 \%\right.$ predicted). However, how hypoxemia relates to disease characteristics is not fully understood.

Methods: In the French Initiatives BPCO real-life cohort, arterial blood gases were routinely collected in most patients. Relationships between severe hypoxemia, defined by a $\mathrm{PaO}_{2}<60 \mathrm{mmHg}$ $(8 \mathrm{kPa})$ and clinical/lung function features, comorbidities and mortality were assessed. In subjects with severe hypoxemia, clinical characteristics and comorbidities were compared between those with non-severe versus severe airflow limitation. Classification and regression trees (CART) were used to define clinically relevant subgroups (phenotypes).

Results: Arterial blood gases were available from 887 subjects, of which 146 (16\%) exhibited severe hypoxemia. Compared to subjects with a $\mathrm{PaO} 2 \geq 60 \mathrm{mmHg}$, the severe hypoxemia group exhibited higher mMRC dyspnea score, lower $\mathrm{FEV}_{1}$, higher RV and RV/TLC, more impaired quality of life, lower 6-minute walking distance, less frequent history of asthma, more frequent diabetes and higher 3-year mortality rate $(14 \%$ versus $8 \%, \mathrm{p}=0.026)$. Compared to subjects with $\mathrm{Pa}_{2}<60 \mathrm{mmHg}$ and $\mathrm{FEV}_{1}<50 \%(\mathrm{n}=115,13 \%)$, those with severe hypoxemia but $\mathrm{FEV} 1 \geq 50 \%$ predicted $(n=31)$ were older, had higher BMI, less hyperinflation, better quality of life and a higher rate of diabetes $(29 \%$ versus $13 \%, \mathrm{p}=0.02)$. Severe hypoxemia was better related to CART-defined phenotypes than to GOLD ABCD classification.

Conclusion: In this cohort of stable COPD subjects, severe hypoxemia was associated with worse prognosis and more severe symptoms, airflow limitation and hyperinflation. Compared to subjects with severe hypoxemia and severe airflow limitation, subjects with severe hypoxemia despite non-severe airflow limitation were older, had higher BMI and more diagnosed diabetes.

Trial Registration: $04-479$.

Keywords: chronic obstructive pulmonary disease, severe hypoxemia, airflow limitation

\section{Background}

Chronic respiratory failure is a major complication in chronic obstructive pulmonary disease (COPD) with both a significant impact on morbidity and mortality and major therapeutic implications. ${ }^{1,2}$ The prevalence of hypoxemia among COPD populations is highly variable, depending on underlying disease characteristics and on comorbidities. Longitudinal data from the Swedish National Register of 
COPD reported a prevalence of $1.4 \%$ for resting hypoxemia. ${ }^{3}$ In moderate-to-severe COPD, 7\% of subjects developed resting hypoxemia after a median follow-up of 5 years. ${ }^{4}$

The lung function characterization of COPD severity is based on the degree of airflow limitation as measured by forced expiratory volume in $1 \mathrm{~s}\left(\mathrm{FEV}_{1}\right)$. In parallel, clinical categories with prognostic and therapeutic relevance are defined with symptoms and exacerbations. Of note, despite its significant burden, hypoxemia is no longer included as a parameter to categorize COPD patients in the recent GOLD combined COPD categorization strategy. ${ }^{5}$ A classic assumption is to consider that severe hypoxemia is only found in subjects with $\mathrm{FEV}_{1}<50 \%$ of predicted. ${ }^{5,6}$ Factors associated with discrepancies between the severity of airflow limitation and hypoxemia are not completely understood.

About 40 years ago, two randomized controlled trials showed that long-term oxygen therapy (LTOT) improves survival in subjects with severe resting hypoxemia at steady state. ${ }^{7,8}$ Since these earlier studies, the profile of subjects with COPD has changed dramatically, while symptomatic pharmacological and non-pharmacological treatments have improved markedly. Although this has not been formally demonstrated, it seems that the disease is discovered less often at a late stage with chronic respiratory failure, and life expectancy has probably increased. In parallel, during the last two decades, major progresses have been made in the understanding of COPD heterogeneity, with the identification of clinically relevant phenotypes, endotypes and treatable traits. Importantly, our group has used classification and regression trees (CART) to develop an algorithm allocating subjects with COPD to clinical phenotypes defined by age, symptoms (dyspnea grade), lung function, nutritional status (BMI) and comorbidities. Cluster and CART analyses were performed in 3 French/Belgian cohorts and further tested inpatients from the COPD Cohorts Collaborative International Assessment (3CIA) initiative. The identified subgroups differed in terms of clinical characteristics, mortality rates and age at death (with poor prognosis groups CART 1 and 4 as compared to good prognosis group CART 5). ${ }^{9}$ How such phenotypes relate to arterial blood gases remains still unknown.

Altogether, despite the profound changes mentioned above in COPD characteristics, treatments and understanding, the burden and determinants of chronic severe hypoxemia has not been reassessed in recent years. Hence, the aims of this study were (1) to assess clinical and lung function features, comorbidities and mortality associated with severe hypoxemia in a real-life COPD cohort, (2) to compare clinical and functional characteristics in subjects with non-severe $\left(\mathrm{FEV}_{1} \geq 50 \%\right.$ predicted) versus severe airflow limitation among those with severe hypoxemia and (3) to compare characteristics of subjects with or without severe hypoxemia, among subjects with severe airflow limitation.

\section{Methods}

\section{Initiatives COPD Cohort}

As previously described, Initiatives BPCO is a rolling reallife cohort which primarily aims to study phenotypes among subjects with COPD followed at 17 French University Hospitals. ${ }^{10}$ Data collected as part of routine practice at inclusion include demographic and anthropometric characteristics, occupational exposures, smoking history, chronic bronchitis, exacerbation frequency, dyspnea assessed by mMRC dyspnea scale, health-related quality of life assessed by the Saint George Respiratory Questionnaire (SGRQ), physician diagnosed comorbidities (asthma, rhinitis, cardiovascular diseases, obesity, diabetes, mechanical limitation, psychological status), medications and post-bronchodilator spirometry (forced expiratory volume in 1 second, $\mathrm{FEV}_{1}$, forced vital capacity, FVC), plethysmography (residual volume, RV, total lung capacity, TLC) ${ }^{11}$ and arterial blood gases (ABG) at rest. Patients included in the present analyses were those with available ABG at rest in stable state. This study was conducted in accordance with the Declaration of Helsinki and was approved by the Ethics Committee of Versailles, France (trial registration \#04-479), and all subjects provided informed written consent.

\section{Arterial Blood Gases (ABG)}

Arterial samples were obtained at rest on room air condition and close to sea level at each site. The following variables from $\mathrm{ABG}$ were collected: $\mathrm{PaO}_{2}$ and $\mathrm{PaCO}_{2}$ $(\mathrm{mmHg})$ and $\mathrm{pH}$. Severe hypoxemia was defined by a $\mathrm{PaO}_{2}<60 \mathrm{mmHg}(8 \mathrm{kPa})$. Subjects in which blood gases were performed using arterialized capillary samples were not retained for analyses.

\section{Association Between Hypoxemia, Clinical/Lung Function Features and Phenotypes}

Relationships between severe hypoxemia and clinical/lung function features, comorbidities and mortality were 
assessed. Severe airflow limitation was defined as postbronchodilator $\mathrm{FEV}_{1}$ less than $50 \%$ predicted postbronchodilator. Phenotypes analyses were based on an algorithm developed using CART in pooled French/ Belgian COPD cohorts (Supplementary Figure S2C) ${ }^{9,10}$ Briefly, this algorithm is based on clinical and lung function variables (including cardiovascular comorbidities, diabetes and respiratory characteristics) and allows allocation of subjects into five classes corresponding to subgroups (phenotypes) identified by cluster analyses with different rates of all-cause mortality at 3 years and ages at death.

\section{Statistical Analyses}

Data are provided as median [Q1; Q3] or n (\%), as appropriate. Univariate comparisons based on the presence/ absence of severe resting hypoxemia and severe airflow obstruction were performed by Chi2 and $t$-test. Correlations were assessed using Pearson's coefficients. Survival was analyzed using 3-year all-cause mortality.

\section{Results}

\section{Subjects Characteristics}

Among 1441 subjects in the cohort at the time of data extraction, $\mathrm{ABG}$ at rest in room air at stable state were available in 887 subjects. More severe airflow limitation and GOLD spirometry stages were found in COPD subjects with versus without available ABG (Supplementary Table $\underline{\mathrm{S} 1})$. No difference was noted in terms of clinical characteristics, comorbidities, and outcomes including three-year mortality rates in patients with versus without available ABG. Characteristics of the 887 COPD subjects included in this analysis are presented in Table 1 . The median values of age and percent predicted (pp) $\mathrm{FEV}_{1}$ were 64 years and $48 \%$, respectively. The majority of the subjects $(74 \%)$ were male.

\section{Arterial Blood Gas Results}

$\mathrm{PaO}_{2}$ distribution is shown in Figure 1. Median $\mathrm{PaO}_{2}$, $\mathrm{PaCO}_{2}$ and $\mathrm{pH}$ levels were $71[63 ; 79] \mathrm{mmHg}, 40$ [37; 43] $\mathrm{mmHg}$ and $7.42 \quad[7.40 ; 7.44]$, respectively. A hundred and forty-six subjects (16\%) exhibited severe hypoxemia defined as $\mathrm{PaO}_{2}<60 \mathrm{mmHg}$ (Figure 2), and 178 subjects (20\%) had hypercapnia defined as $\mathrm{PaCO}_{2}$ $\geq 45 \mathrm{mmHg}$ with $6 \%$ of the subjects with a $\mathrm{PaCO}_{2} \geq 52$ mmHg (Supplementary Figure S1A). Fifteen subjects had acidosis, defined as $\mathrm{pH}<7.35$ (Supplementary Figure $\mathrm{S} 1 \mathrm{~A}$ and $\mathrm{B}) . \mathrm{PaO}_{2}$ and $\mathrm{PaCO}_{2}$ values were weakly correlated (Figure 1B).

\section{Hypoxemia According to Airflow Obstruction and Hyperinflation}

Compared to subjects with a $\mathrm{PaO}_{2} \geq 60 \mathrm{mmHg}$, the severe hypoxemia group exhibited higher mMRC dyspnea score, lower FEV ${ }_{1}$, higher RV and RV/TLC, lower DLCO, more impaired quality of life, lower 6-minute walking distance, less frequent history of asthma, and higher 3-year mortality rate $(14 \%$ versus $8 \%)$ (all, $p<0.05$, Table 1$)$. The relationships between $\mathrm{PaO}_{2}$ and $\mathrm{FEV}_{1}$ and the distribution of COPD subjects using thresholds of $60 \mathrm{mmHg} \mathrm{PaO}_{2}$ for severe hypoxemia and $50 \% \mathrm{FEV}_{1}$ for severe airway limitation are presented in Figure 2. Among subjects with severe hypoxemia $(n=146), 31(21.2 \%, 3 \%$ of the whole study population) had a $\mathrm{FEV}_{1} \geq 50 \%$ predicted. Compared to subjects with severe hypoxemia and $\mathrm{FEV}_{1}<50 \%$ $(\mathrm{n}=115)$, this group was older, had higher BMI, lower RV and RV/TLC, a better quality of life (SGRQ score) and a higher rate of diabetes (29\% versus $13 \%$ ) (all, $\mathrm{p}<0.05$, Table 2).

Among subjects with severe airflow obstruction $(n=470), 355$ subjects $(75.5 \%, 40 \%$ of the whole study population) had a $\mathrm{PaO}_{2}>60 \mathrm{mmHg}$. Compared to subjects with severe hypoxemia and $\mathrm{FEV}_{1}<50 \%$, this group had higher BMI, a lower rate of OSA, higher DLCO, and higher 6-min walking distance (all, $\mathrm{p}<0.05$, Table 2).

\section{Distribution of $\mathrm{PaO}_{2}$ According to Spirometric Grade of Airflow Obstruction, GOLD Stage 2020 and CART-Defined Phenotypes}

Severe hypoxemia was, respectively, present in $10 \%, 7 \%$, $29 \%$ and $32 \%$ of subjects in spirometric GOLD 1, 2, 3 and 4 stages, respectively (Figure 3A-D). GOLD ABCD classification did not allow a better discrimination of patients relative to severe hypoxemia (Supplementary Figure S2A). Interestingly, severe hypoxemia was highly prevalent in the CART-defined groups with the poorest prognosis (CART 1 and 4) with, respectively, 26.7\% and 35.6\% of severely hypoxemic subjects. Conversely, the CART 5 group, which is associated with a good prognosis, comprised of very few subjects $(2.4 \%)$ with severe hypoxemia (Figure 3E-I, Supplementary Figure S2B).

\section{Discussion}

Few recent studies in "modern" COPD populations have focused on the link between clinical phenotypes, outcomes 
Table I Comparison Between COPD Subjects with and without Severe Hypoxemia

\begin{tabular}{|c|c|c|c|c|}
\hline & All & $\mathrm{PaO}_{2}<60 \mathrm{mmHg}$ & $\mathrm{PaO}_{2} \geq 60 \mathrm{mmHg}$ & $p$ \\
\hline$n, \%$ & 887 & $146(16 \%)$ & $74 \mid(84 \%)$ & \\
\hline Age, yr & $64[57 ; 72]$ & $65[58 ; 74]$ & $64[57 ; 72]$ & NS \\
\hline Sex, $M / F$ & $653 / 234$ & $110 / 36$ & $543 / 198$ & NS \\
\hline Smoking, pack-yr & $40[25 ; 59]$ & $39[24 ; 75]$ & $41[25 ; 59]$ & NS \\
\hline $\mathrm{BMI}<18.5 \mathrm{~kg} \cdot \mathrm{m}^{2}{ }^{2}$ & 81 (9\%) & $21(14 \%)$ & $60(8 \%)$ & 0.02 \\
\hline $\mathrm{BMI}>30 \mathrm{~kg} \cdot \mathrm{m}^{-2}$ & $201(23 \%)$ & $31(21 \%)$ & $170(23 \%)$ & NS \\
\hline Exacerbations in previous year, $\mathrm{n}$ & I $[0 ; 2]$ & I $[0 ; 3]$ & I $[0 ; 3]$ & NS \\
\hline History of asthma & $125(14 \%)$ & $13(9 \%)$ & $112(15 \%)$ & 0.049 \\
\hline Hypertension & $344(39 \%)$ & $58(40 \%)$ & $286(39 \%)$ & NS \\
\hline Coronary artery disease & $123(14 \%)$ & $23(16 \%)$ & $100(14 \%)$ & NS \\
\hline Left heart failure & $101(11 \%)$ & $17(12 \%)$ & $84(11 \%)$ & NS \\
\hline Diabetes & $126(14 \%)$ & $24(16 \%)$ & $102(14 \%)$ & NS \\
\hline Obstructive SleepApnea & $86(10 \%)$ & $16(11 \%)$ & $70(10 \%)$ & NS \\
\hline mMRC dyspnea grade & $2[1 ; 3]$ & $3[2 ; 3]$ & $2[1 ; 3]$ & $<0.0001$ \\
\hline $\mathrm{paO}_{2}, \mathrm{mmHg}$ & $71[63 ; 79]$ & 56 [52: 59] & $73[65 ; 80]$ & $<0.0001$ \\
\hline $\mathrm{paCO}_{2}, \mathrm{mmHg}$ & $40[37 ; 43]$ & $44[40 ; 50]$ & $39[36 ; 43]$ & $<0.0001$ \\
\hline $\mathrm{pH}$ & $7.42[7.40 ; 7.44]$ & $7.42[7.40 ; 7.45]$ & $7.42[7.40 ; 7.44]$ & 0.6614 \\
\hline $\mathrm{FEV}_{1}, \%$ predicted & $48[33 ; 63]$ & $35[25 ; 47]$ & $51[36 ; 65]$ & $<0.0001$ \\
\hline FVC, \% predicted & $82[68 ; 98]$ & 71 [58; 92] & $83[69 ; 99]$ & $<0.0001$ \\
\hline RV, \% predicted & $166[131 ; 209]$ & $186[143 ; 229]$ & $161[131 ; 205]$ & 0.0063 \\
\hline TLC, \% predicted & $113[100 ; 129]$ & $117[101 ; 131]$ & $113[100 ; 128]$ & NS \\
\hline RV/TLC, \% & $57[48 ; 65]$ & $64[54 ; 69]$ & $56[48 ; 63]$ & $<0.0001$ \\
\hline $\mathrm{DLCO}, \mathrm{mL} / \mathrm{min} / \mathrm{mmHg}$ & $13.8[9.2 ; 18.9]^{\mathrm{a}}$ & $8.0[5.6 ; 10.9]^{\mathrm{b}}$ & $14.8[11.0 ; 19.7]^{c}$ & $<0.0001$ \\
\hline SGRQ & $37[23 ; 52]$ & $57[42-68]$ & $45[32 ; 58]$ & $<0.0001$ \\
\hline 6MWD & $400[305 ; 470]^{d}$ & $305[266 ; 393]^{\mathrm{e}}$ & $410[320 ; 480]^{f}$ & $<0.0001$ \\
\hline 3-year mortality & 79 (9\%) & $20(14 \%)$ & $59(8 \%)$ & 0.026 \\
\hline
\end{tabular}

Notes: 887 COPD subjects were included ( 146 having $\mathrm{PaO}_{2}<60 \mathrm{mmHg}$ and $74 \mathrm{I}$ having $\left.\mathrm{PaO}_{2} \geq 60 \mathrm{mmHg}\right)$. Data are $\mathrm{n}(\%)$ or median [interquartiles]. Missing values are ${ }^{a}$ $n=549,{ }^{b} n=97,{ }^{c} n=460,{ }^{d} n=370,{ }^{e} n=71,{ }^{f} n=299$.

Abbreviations: ABG, arterial blood gas; BMI, body mass index; FEVI, forced expiratory volume in I second; FVC, forced vital capacity; OSA, obstructive sleep apnea; mMRC, modified medical research council; NS, non-significant; SGRQ, Saint Georges respiratory questionnaire; TLC, total lung capacity; RV, residual volume; 6MWD, 6-minute walking distance.

and resting hypoxemia. Our results in a real-life cohort of stable COPD subjects covering the whole spectrum of light-to-very severe airflow obstruction showed that severe hypoxemia was present in $10 \%, 7 \%, 29 \%$ and $32 \%$ of subjects from GOLD 1 to 4 spirometric stages, respectively. This feature was associated with worse prognosis, more severe symptoms, airflow limitation and hyperinflation. Patients with severe hypoxemia but non-severe airflow limitation were characterized by older age, higher BMI, less hyperinflation, and more frequent diabetes. Hypoxemia was more closely linked to CART-defined phenotypes than to GOLD classifications. 
A

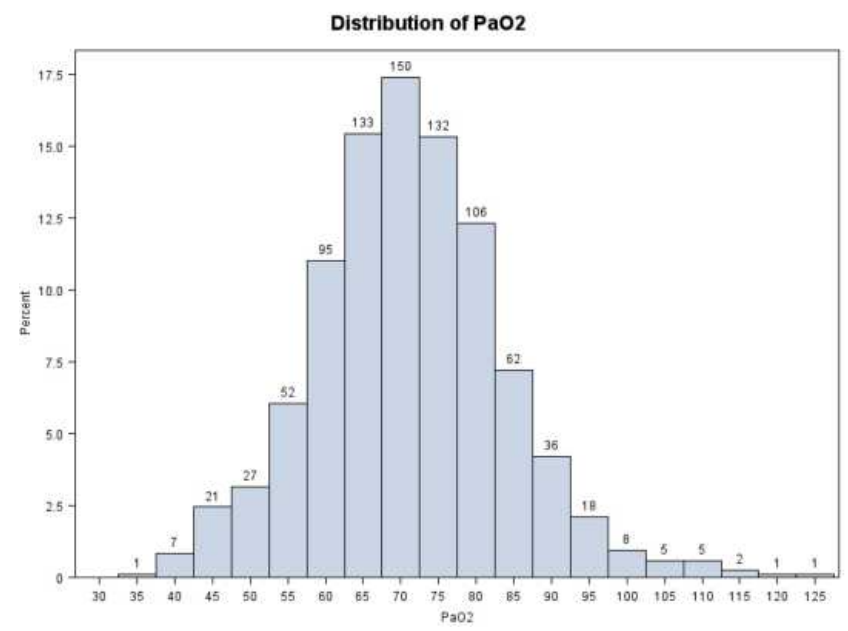

B

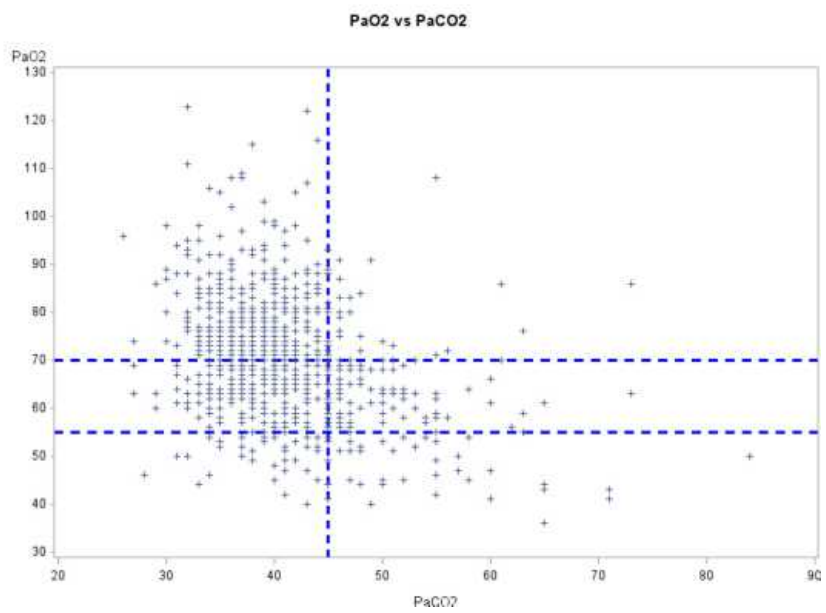

Figure I Distribution of $\mathrm{PaO}_{2}(\mathbf{A})$ and relationships between $\mathrm{PaO} 2$ and $\mathrm{PaCO} 2(\mathbf{B}) .887$ COPD subjects were included. Values are in mmHg.

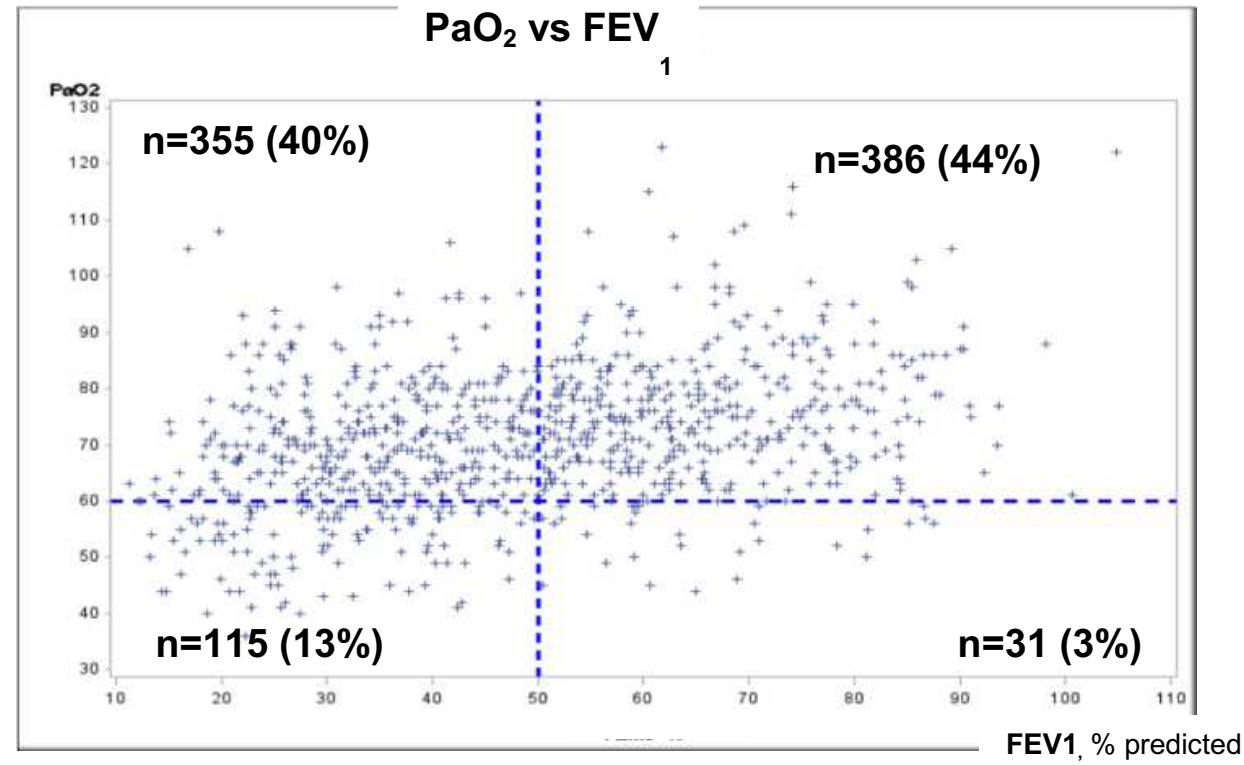

Figure 2 Relationships between $\mathrm{PaO}_{2}$ and $\mathrm{FEV}$, and distribution of COPD subjects for severe hypoxemia and severe airflow limitation. $887 \mathrm{COPD}$ subjects were included. High $\mathrm{PaO}_{2} /$ high $\mathrm{FEV}_{1}$ are in the right and upper part of the graph. High $\mathrm{PaO}_{2} /$ low $\mathrm{FEV}_{1}$ are in the left and upper part of the graph. Low paO $/$ high $\mathrm{FEV}$, are in the right and lower part of the graph. Low $\mathrm{PaO}_{2} /$ high $\mathrm{FEV}$, are in the left and lower part of the graph. Values are in $\mathrm{mmHg}$ or \%.

The prevalence of severe hypoxemia in COPD is higher in this cohort than previously reported in other reallife COPD cohorts, where it ranged from 1.4 to $5 \%{ }^{3,4}$ This likely relates to a selection bias in our study including COPD subjects with available ABG follow-up in University Hospitals, and thus probably more severe than in other cohorts. Our results showing worse lung function and prognosis associated with severe hypoxemia are in line with previously published data. ${ }^{12,13}$ Contrary to a classical assumption, we confirm here that severe hypoxemia cannot be ruled out in case of non-severe airflow obstruction.

An interesting finding of the present study is the demonstration that the group of subjects with severe hypoxemia despite non-severe airflow limitation was older, had higher BMI and more diagnosed diabetes. The prevalence of diabetes was comparable to what has been reported in previous studies. These findings could 
Table 2 Comparison Between COPD Subjects with and without Severe Hypoxemia, with or without Severe Airflow Obstruction

\begin{tabular}{|c|c|c|c|c|}
\hline & $\begin{array}{c}\mathrm{PaO}_{2}<60 \mathrm{mmHg} \\
\mathrm{FEV}_{1}<50 \% \text { (I) }\end{array}$ & $\begin{array}{c}\mathrm{PaO}_{2}<60 \mathrm{mmHg} \\
\mathrm{FEV}_{\mathrm{I}} \geq \mathbf{5 0 \%}(2)\end{array}$ & $\begin{array}{c}\mathrm{PaO}_{2} \geq 60 \mathrm{mmHg} \\
\mathrm{FEV}_{\mathrm{l}} \geq 50 \% \text { (3) }\end{array}$ & $\begin{array}{c}\mathrm{PaO}_{2} \geq 60 \mathrm{mmHg} \mathrm{FEV}_{\mathrm{I}} \\
<50 \%(4)\end{array}$ \\
\hline $\mathrm{n}, \%$ & $115(13 \%)$ & $31(3 \%)$ & 386 & $355(40 \%)$ \\
\hline Age, yr & $64[57 ; 73]$ & $71[64 ; 77]^{\#,+}$ & $65[58 ; 73]$ & $63[57 ; 70]$ \\
\hline Sex, $M / F$ & $85 / 30$ & $25 / 6$ & $271 / 115$ & $272 / 83$ \\
\hline Smoking, pack-yr & $39[25 ; 56]$ & $40[20 ; 63]$ & $40[25 ; 55]$ & $4 I[25 ; 6 I]$ \\
\hline $\mathrm{BMI}<18,5 \mathrm{~kg} \cdot \mathrm{m}^{2}{ }^{2}$ & $20(17 \%)$ & $1(3 \%)^{+}$ & 17 (4.4\%) & $43(12 \%)$ \\
\hline $\mathrm{BMI}>30 \mathrm{~kg} \cdot \mathrm{m}^{2}{ }^{2}$ & $22(19 \%)$ & $9(29 \%)$ & $109(29.2 \%)$ & $61(17 \%)$ \\
\hline Exacerbations in previous year, $n$ & I $[0 ; 3]$ & I $[0 ; 3]$ & I $[0 ; 2]$ & $2[1 ; 3]$ \\
\hline History of asthma & $13(11 \%)$ & $0(0 \%)$ & $54(14 \%)$ & $58(16 \%)$ \\
\hline Hypertension & 45 (39\%) & $13(42 \%)$ & $154(40 \%)$ & $132(37 \%)$ \\
\hline Coronaryartery disease & $16(14 \%)$ & $7(23 \%)$ & $56(15 \%)$ & $44(12 \%)$ \\
\hline Heart failure & $10(9 \%)$ & $7(23 \%)$ & 43 (11\%) & $4 \mid(11 \%)$ \\
\hline Diabetes & 15 (13\%) & $9(29 \%)^{+}$ & 48 ( $12 \%)$ & $54(15 \%)^{\#}$ \\
\hline Obstructive SleepApnea & 14 (I2\%) & $2(6.5 \%)$ & 44 (I2\%) & $24(7 \%)$ \\
\hline mMRC scale & $3[2 ; 3]$ & $2[2 ; 3]$ & $\mathrm{I}[\mathrm{I} ; 2]^{\#}$ & $2[1 ; 3]^{\#}$ \\
\hline $\mathrm{FEV}_{\mathrm{l}}, \%$ predicted & $30[23 ; 39]$ & $61[55 ; 71]^{+}$ & $64[57 ; 74]$ & $35[27 ; 42]$ \\
\hline FVC, \% predicted & $69[54 ; 81]$ & $99[76 ; 110]^{+}$ & $95[84 ; 107]$ & $71[59 ; 82]$ \\
\hline RV, \% predicted & $202[164 ; 244]$ & $124[92 ; 155]^{+}$ & $142[12|;| 70]$ & $197[155 ; 246]^{\#}$ \\
\hline TLC, \% predicted & $122[107 ; 135]$ & $94[85 ; 117]^{+}$ & $109[98 ; 122]$ & $119[104 ; 134]^{\#}$ \\
\hline $\mathrm{RV} / \mathrm{TLC}, \%$ & $65[60 ; 71]$ & $48[42 ; 54]^{+}$ & $50[44 ; 57]$ & $63[56 ; 60]$ \\
\hline $\mathrm{DLCO}, \mathrm{mL} / \mathrm{min} \mathrm{mmHg}$ & $7.7[4.9 ; 10.6]^{\mathrm{a}}$ & $8.6[7.9 ; \mid 4.6]^{+, b}$ & $16.8[13.2 ; 22.5]^{c}$ & $12.2[7.8 ; 16.4]^{\mathrm{d}, \#}$ \\
\hline $\mathrm{PaCO}_{2}$ & $45[42 ; 53]$ & $39[35 ; 42]$ & $38[35 ; 4 I]$ & $40[37 ; 43]$ \\
\hline SGRQ & $58[46 ; 70]$ & $44[39 ; 59]^{+}$ & $38[26 ; 5 I]$ & $54[4 I ; 64]$ \\
\hline 6MWD & $303[255 ; 372]^{\mathrm{e}}$ & $315[283 ; 399]^{f}$ & $430[370 ; 500]^{g}$ & $374[300 ; 445]^{\text {h, \# }}$ \\
\hline 3-year mortality & 15 (13\%) & $5(16 \%)$ & $18(5 \%)$ & $4 \mathrm{I}(12 \%)^{\#}$ \\
\hline
\end{tabular}

Notes: 887 COPD subjects were included $\left(I I 5\right.$ having $\mathrm{PaO}_{2}<60 \mathrm{mmHg}$ and FEVI $<50 \%, I I 5$ having $\mathrm{PaO}_{2}<60 \mathrm{mmHg}$ and FEVI $\geq 50 \%, 386$ having $\mathrm{PaO} 2 \geq 60 \mathrm{mmHg}$ and FEVI $\geq 50 \%$ and 355 having $\mathrm{PaO}_{2} \geq 60 \mathrm{mmHg}$ and FEVI $<50 \%$ ). $n$ (\%) or median [interquartiles] ${ }^{+} I$ versus $2,{ }^{\#} 2$ versus 4 . Missing values are ${ }^{c} n=220,{ }^{d} n=240,{ }^{a} n=76,{ }^{b} n=21$, $g_{n}=163,{ }^{h} n=136,{ }^{e} n=57,{ }^{f} n=14$.

Abbreviations: BMl, body mass index; FEV ${ }_{1}$, forced expiratory volume in I second; FVC, forced vital capacity; mMRC, modified medical research council; SGRQ, Saint Georges respiratory questionnaire; TLC, total lung capacity; RV, residual volume; 6MWD, 6-minute walking distance.

suggest a potential interaction between diabetes and hypoxemia. Previous studies found a higher prevalence of diabetes in COPD. ${ }^{14}$ Although experimental hypoxia produces insulin resistance in animal models, ${ }^{15}$ evidence in humans is conflicting. ${ }^{16}$ Besides, cross-sectional studies showed that adults with diabetes have lower $\mathrm{FEV}_{1}$ compared with non-diabetic subjects. ${ }^{17}$ The mechanisms underlying hypoxemia in diabetes remain to be understood and may involve increased obesity, reduced physical activity, increased cigarette smoke, or diseaserelated modifications including inflammation and/or oxidative stress. ${ }^{18}$ We can hypothesize that microangiopathy due to type 2 diabetes in the alveolar capillaries and pulmonary arterioles could also be incriminated. ${ }^{18}$ Obesity may participate to explain hypoxemia in patients with non-severe airflow limitation, as suggested by the 

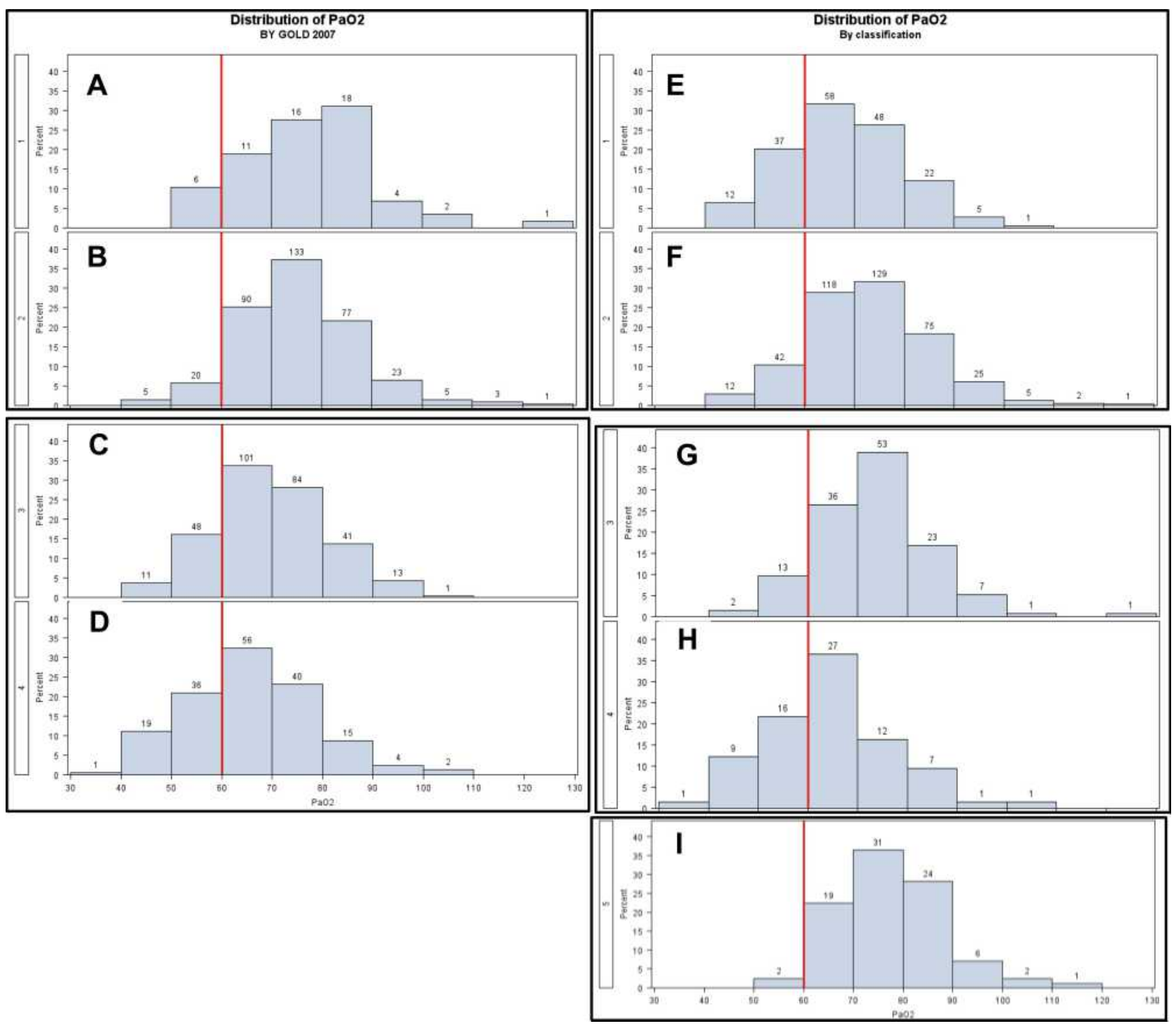

Figure 3 Repartition of $\mathrm{PaO}_{2}$ according to GOLD stage 2007 I to 4 (A-D, respectively) or according to CART classification I to 5 (E-I, respectively) (with a cut-off at 60 $\mathrm{mmHg}$ (8)). 887 COPD subjects were included.

increased proportion of patients with higher BMI in discordant (non-severe airflow limitation) than in concordant (severe airflow limitation) hypoxemic patients. In obese patients, hypoxemia can relate to ventilation/perfusion mismatch in lower areas of the lungs or to alveolar hypoventilation. This latter hypothesis is unlikely since $\mathrm{PaCO} 2$ is not higher in the discordant than in the concordant hypoxemic group $(39[35 ; 42] \mathrm{mmHg}$ versus 40 [37; 43] mmHg).

Finally, phenotypes analyses using the CART classification indicated that severe hypoxemia was highly prevalent in the poor prognosis groups CART 1 and 4 whereas very few severe hypoxemic subjects were found in the good prognosis group CART 5 group, highlighting that severe hypoxemia is an important feature associated with worse prognosis in COPD. ${ }^{9}$ The inclusion of hypoxemia in the assessment of COPD severity may help to better categorize subjects in terms of prognosis and could eventually improve CART classification. Patients from the CART 5 group may not require $\mathrm{ABG}$.

As previously reported, severe hypoxemia was associated with lower DLCO in our study than in others, where a low DLCO has been associated with specific clinical profiles including more severe dyspnea. ${ }^{1019-21}$ However, it must be pointed out that DLCO data were often missing in our cohort, thus preventing us from deeper analyses regarding the relevance of this variable. Similarly, 6-minute walking distance was lower in severe hypoxemic subjects, but 
data were often missing again. Another limitation is that comorbidities are only diagnosed-comorbidities.

\section{Conclusion}

In this cohort of stable COPD subjects, severe hypoxemia was associated with worse prognosis and more severe symptoms, airflow limitation and hyperinflation. Compared to subjects with severe hypoxemia and severe airflow limitation, subjects with severe hypoxemia despite non-severe airflow limitation were older, had higher BMI and more diagnosed diabetes, underlining that the mechanisms of hypoxemia in COPD are not limited to the respiratory component of the multi-morbidity that affects these patients. CART-based classification may alleviate the need for ABGs in some patients' categories better than GOLD classifications.

\section{Abbreviations}

$\mathrm{ABG}$, arterial blood gases; BMI, body mass index; CART, classification and regression tree; COPD, chronic obstructive pulmonary disease; DLCO, diffusing capacity of the lung for carbon monoxide; $\mathrm{FEV}_{1}$, forced expiratory volume in one second; FVC, forced vital capacity; GOLD, global initiative for obstructive lung disease; HAD, hospital anxiety and depression scale; mMRC, modified Medical Research Council; OSAS, obstructive sleep apnea syndrome; RV, residual volume; SGRQ, Saint George's respiratory questionnaire; TLC, total lung capacity.

\section{Data Sharing Statement}

The datasets used and analyzed during the current study are available from the corresponding authors on reasonable request.

\section{Ethics Approval and Consent to Participate}

This study was conducted in accordance with the Declaration of Helsinki and study protocol has been approved by the Ethics Committee of Versailles Saint Quentin University, authorization number 04-479, for protection of human beings involved in biomedical research. The study has also been approved by CCTIRS (Comité Consultatif sur le Traitement de l'Information en matière de Recherche dans le domaine de la Santé), on the 6thJanuary, 2005 (04-479). All subjects provided written consent.

\section{Consent for Publication}

All subjects provided written consent. All authors provided consent to publication.

\section{Acknowledgments}

We thank the initiatives BPCO study group P.R. Burgel (Paris), G. Deslee (Reims), P. Surpas (Charnay), O. Le Rouzic (Lille), T. Perez (Lille), N. Roche (Paris), G. Brinchault-Rabin (Rennes), D. Caillaud (ClermontFerrand), P. Chanez (Marseille), I. Court-Fortune (SaintEtienne), R. Escamilla (Toulouse), G. Jebrak (Paris), P. Nesme-Meyer (Lyon), M. Zysman (Bordeaux), A. Guillaumot (Nancy), C. Pinet (Toulon) and Brigitte Risse (ARAIRLOR, Association régionale d'aide aux insuffisants respiratoires de Lorraine, Nancy).

\section{Author Contributions}

All authors made a significant contribution to the work reported, whether that is in the conception, study design, execution, acquisition of data, analysis and interpretation, or in all these areas; took part in drafting, revising or critically reviewing the article; gave final approval of the version to be published; have agreed on the journal to which the article has been submitted; and agree to be accountable for all aspects of the work.

\section{Funding}

The Initiatives BPCO cohort is supported by Boehringer Ingelheim France since its creation and has been funded by Pfizer until 2015, in the form of unrestricted grants. The sponsors fund the database, statistical analyses, meetings and submission fees when required. They do not participate in decisions regarding collected data, analyses, article writing and submission. For all these aspects, the Initiatives BPCO group works in total independence.An abstract describing the results presented here was presented at ERS International Congress 2019 Madrid/ Spain, and published in the European Respiratory Journal http://old.erscongress.org/programme-2019.

\section{Disclosure}

$\mathrm{MZ}$ reports grants and personal fees from Boehringer Ingelheim, grants and personal fees from Novartis, personal fees from Chiesi, personal fees from Astra Zeneca and personal fees from GSK outside the submitted work.

PRB reports personal fees from Aptalis, personal fees from Astra-Zeneca, grants and personal fees from Boehringer 
Ingelheim, personal fees from Chiesi, personal fees from GSK, personal fees from Novartis, personal fees from Pfizer, personal fees from Vertex, personal fees from Zambon, personal fees from Insmed, outside the submitted work.

ICF reports grants and personal fees from Boehringer Ingelheim, grants and personal fees from Novartis, and GSK outside the submitted work.

GBR reports grants and personal fees from Boehringer Ingelheim, grants and personal fees from Novartis, grants and personal fees from Astra Zeneca, personal fees and nonfinancial support from Chiesi, outside the submitted work.

PNM reports grants and personal fees from Boehringer Ingelheim, grants and personal fees from NOVARTIS, personal fees and non-financial support from Chiesi, outside the submitted work.

PS reports grants and personal fees from Boehringer Ingelheim outside the submitted work.

GD reports personal fees from Novartis, personal fees and grants from Astra Zeneca, personal fees from BTG/ PneumRx, personal fees from Chiesi, personal fees from Boehringer Ingelheim, personal fees from GSK, outside the submitted work.

TP reports personal fees from Boehringer Ingelheim, personal fees from Novartis, personal fees from GSK, personal fees from Chiesi, personal fees from Pierre Fabre, outside the submitted work.

OLR reports grants and personal fees personal fees and non-financial support from Astra Zeneca, Boehringer Ingelheim, Chiesi, Lilly and Novartis; non-financial support from Glaxo Smith Kline, Correvio, Mayoli, Mylan, MSD, PulmonX, Zambon, Novartis, MundiPharma, Pfizer, Teva, Santelys Association, Vertex and Vitalaire, all outside the submitted work.

GJ reports personal fees from Boehringer Ingelheim, personal fees from GSK, personal fees from Novartis, personal fees from Menarini, personal fees from Astra Zeneca, personal fees from Chiesi, outside the submitted work.

PC reports personal fees from Boehringer Ingelheim, personal fees from GSK, personal fees and grants from ALK, personal fees and grants from Almirall, personal fees and grants from Boehringer-Ingelheim, personal fees from Novartis, personal fees from Teva, personal fees from Astra Zeneca, grants and personal fees from Chiesi, personal fees from Sanofi, personal fees and non-financial support from SNCF, personal fees from GlaxoSmithKline, grants and personal fees from Sanofi-Aventis, grants from Amu, outside the submitted work.
JLP reports grants from iBPCO association, during the conduct of the study.

DC has nothing to disclose.

NR reports grants and personal fees from Boehringer Ingelheim, grants and personal fees from Novartis, grant and personal fees from Pfizer, grants and personal fees from GSK, personal fees from AstraZeneca, personal fees from Chiesi, personal fees from Sanofi, personal fees from Zambon, personal fees and grants from Boehringer Ingelheim, outside the submitted work.

\section{References}

1. Albert RK, Au DH, Blackford AL, et al.; Long-Term Oxygen Treatment Trial Research Group. A randomized trial of long-term oxygen for COPD with moderate desaturation. $N$ Engl J Med. 2016;375:1617-1627.

2. Bressler RB, Awe RJ. Oxygen therapy in chronic obstructive lung disease. Ann Intern Med. 1981;94:410. doi:10.7326/0003-4819-943-410 1

3. Sundh J, Ekström M. Risk factors for developing hypoxic respiratory failure in COPD. Int $J$ Chron Obstruct Pulmon Dis. 2017;12:2095-2100. doi:10.2147/COPD.S140299

4. Wells JM, Estepar RS, McDonald MN, et al. Clinical, physiologic, and radiographic factors contributing to development of hypoxemia in moderate to severe COPD: a cohort study. BMC Pulm Med. 2016;16:169. doi:10.1186/s12890-016-0331-0

5. Available from: https:/goldcopd.org/wp-content/uploads/2019/11/ GOLD-2020-REPORT-ver1.0wms.pdf. Accessed April 20, 2021.

6. Lim S, MacRae KD, Seed WA, Roberts CM. The value of forced expiratory volume in $1 \mathrm{~s}$ in screening subjects with stable COPD for $\mathrm{PaO} 2<7.3 \mathrm{kPa}$ qualifying for long-term oxygen therapy. Respir Med. 1998;92(9):1122-1126. doi:10.1016/s0954-6111(98)90405-x

7. Nocturnal Oxygen Therapy Trial Group. Continuous or nocturnal oxygen therapy in hypoxemic chronic obstructive lung disease: a clinical trial, Ann Intern Med. 1980;93(3):391-398. PMID: 6776858. doi:10.7326/0003-4819-93-3-391

8. Report of the Medical Research Council Working Party. Long term domiciliary oxygen therapy in chronic hypoxic cor pulmonale complicating chronic bronchitis and emphysema. Lancet. 1981;1 (8222):681-686. PMID: 6110912.

9. Burgel PR, Paillasseur JL, Janssens W, et al. A simple algorithm for the identification of clinical COPD phenotypes. Eur Respir J. 2017;50:1701034. doi:10.1183/13993003.01034-2017

10. Burgel PR, Paillasseur JL, Caillaud D, et al. Clinical COPD phenotypes: a novel approach using principal component and cluster analyses. Eur Respir J. 2010;36:531-539. doi:10.1183/09031936.00175109

11. Miller MR, Hankinson J, Brusasco V, et al. Standardisation of spirometry. Eur Respir J. 2005;26:319-338. doi:10.1183/09031936.05.00034805

12. Chaouat A, Weitzenblum E, Kessler R, et al. A randomized trial of nocturnal oxygen therapy in chronic obstructive pulmonary disease patients. Eur Respir J. 1999;14:1002-1008. doi:10.1183/ 09031936.99.14510029

13. Górecka D, Gorzelak K, Sliwiński P, Tobiasz M, Zieliński J. Effect of long-term oxygen therapy on survival in patients with chronic obstructive pulmonary disease with moderate hypoxaemia. Thorax. 1997;52:674-679. doi:10.1136/thx.52.8.674

14. Cazzola M, Bettoncelli G, Sessa E, Cricelli C, Biscione G. Prevalence of comorbidities in patients with chronic obstructive pulmonary disease. Respiration. 2010;80:112-119. doi:10.1159/ 000281880 
15. Raff H, Bruder ED, Jankowski BM. The effect of hypoxia on plasma leptin and insulin in newborn and juvenile rats. Endocrine. 1999;11:37-39. doi:10.1385/ENDO:11:1:37

16. Cheng N, Cai W, Jiang M, Wu S. Effect of hypoxia on blood glucose, hormones, and insulin receptor functions in newborn calves. Pediatr Res. 1997;41:852-856. doi:10.1203/00006450-199706000-00009

17. Klein OL, Krishnan JA, Glick S, Smith LJ. Systematic review of the association between lung function and Type 2 diabetes mellitus. Diabet Med. 2010;27:977-987. doi:10.1111/j.14645491.2010.03073.x

18. Rogliani P, Calzetta L, Segreti A, Barrile A, Cazzola M. Diabetes mellitus among outpatients with COPD attending a university hospital. Acta Diabetol. 2014;51:933-940. doi:10.1007/s00592-0140584-0
19. Thabut G, Dauriat G, Stern JB, et al. Pulmonary hemodynamics in advanced COPD candidates for lung volume reduction surgery or lung transplantation. Chest. 2005;127:1531-1536. doi:10.1378/ chest.127.5.1531

20. Olsson KM, Fuge J, Meyer K, Welte T, Hoeper MM. More on idiopathic pulmonary arterial hypertension with a low diffusing capacity. EurRespirJ. 2017;50:1700354.

21. Kovacs G, Agusti A, Barberà JA, et al. Pulmonary vascular involvement in chronic obstructive pulmonary disease. Is there a pulmonary vascular phenotype? Am J Respir Crit Care Med. 2018;198:1000-1011. doi:10.1164/rccm.201801-0095PP

\section{Publish your work in this journal}

The International Journal of COPD is an international, peer-reviewed journal of therapeutics and pharmacology focusing on concise rapid reporting of clinical studies and reviews in COPD. Special focus is given to the pathophysiological processes underlying the disease, intervention programs, patient focused education, and self management protocols. This journal is indexed on PubMed Central, MedLine and CAS. The manuscript management system is completely online and includes a very quick and fair peer-review system, which is all easy to use. Visit http://www.dovepress.com/testimonials.php to read real quotes from published authors. 